\title{
Tobacco Use Changes and Perceived Health Risks among Current Tobacco Users during the COVID-19 Pandemic
}

\author{
Jessica M. Yingst ${ }^{1, * \mathbb{D}}$, Nicolle M. Krebs ${ }^{1} \mathbb{D}$, Candace R. Bordner ${ }^{1,2}$, Andrea L. Hobkirk ${ }^{1,2} \mathbb{D}$, Sophia I. Allen ${ }^{1} \mathbb{D}$ \\ and Jonathan Foulds 1,2 (D) \\ 1 Center for Research on Tobacco and Health, Department of Public Health Sciences, Penn State University \\ College of Medicine, Hershey, PA 17033, USA; nkrebs@pennstatehealth.psu.edu (N.M.K.); \\ cbordner@pennstatehealth.psu.edu (C.R.B.); ahobkirk@pennstatehealth.psu.edu (A.L.H.); \\ sallen3@phs.psu.edu (S.I.A.); jfoulds@psu.edu (J.F.) \\ 2 Center for Research on Tobacco and Health, Department of Psychiatry and Behavioral Health, Penn State \\ University College of Medicine, Hershey, PA 17033, USA \\ * Correspondence: jyingst@phs.psu.edu; Tel.: +1-717-531-4637
}

Citation: Yingst, J.M.; Krebs, N.M.; Bordner, C.R.; Hobkirk, A.L.;

Allen, S.I.; Foulds, J. Tobacco Use Changes and Perceived Health Risks among Current Tobacco Users during the COVID-19 Pandemic. Int. J. Environ. Res. Public Health 2021, 18, 1795. https://doi.org/10.3390/ ijerph18041795

Academic Editor: Paul B. Tchounwou Received: 31 December 2020

Accepted: 9 February 2021

Published: 12 February 2021

Publisher's Note: MDPI stays neutral with regard to jurisdictional claims in published maps and institutional affiliations.

Copyright: (c) 2021 by the authors. Licensee MDPI, Basel, Switzerland. This article is an open access article distributed under the terms and conditions of the Creative Commons Attribution (CC BY) license (https:/ / creativecommons.org/licenses/by/ $4.0 /)$.

\begin{abstract}
COVID-19 has become a global pandemic, with over 81 million cases worldwide. To assess changes in tobacco use as a result of the pandemic, we surveyed a convenience sample of current tobacco users between April and June 2020. The sample was taken from a tobacco user research registry $(n=3396)$ from the Penn State College of Medicine in Hershey, Pennsylvania, USA. Participants who responded to the survey and were eligible for this study ( $n=291)$ were $25.6 \%$ male, $93 \%$ white, and had a mean age of $47.3(\mathrm{SD}=11.6)$ years. There were no reports of participants testing positive for COVID-19, but $21.7 \%$ reported experiencing symptoms associated with the virus. Most participants $(67 \%)$ believed that their risk of contracting COVID-19 was the same as non-tobacco users, but $57.7 \%$ believed that their risk of serious complications, if infected, was greater compared to non-tobacco users. A total of $28 \%$ reported increasing their cigarette use during the pandemic. The most common reasons for increased use were increased stress, more time at home, and boredom while quarantined. Nearly $15 \%$ reported decreasing their tobacco use. The most common reasons for reduced use were health concerns and more time around non-smokers (including children). A total of $71(24.5 \%)$ users reported making a quit attempt. Characterizing these pandemic-related changes in tobacco use may be important to understanding the full scope of subsequent health outcomes resulting from the pandemic. Tobacco cessation resources should be tailored to allow for safe, appropriate access for those interested in quitting.
\end{abstract}

Keywords: tobacco use; cigarette smoking; e-cigarettes; COVID-19; pandemic; quit attempts; cessation; stress

\section{Introduction}

In December 2019, the first cases of a novel coronavirus disease (COVID-19) were reported in Wuhan, Hubei province, China [1]. The disease quickly spread and has become a pandemic, with over 81 million cases and 1.7 million deaths worldwide as of 28 December 2020 [2]. COVID-19 is mainly a disease of the respiratory tract characterized by a severe acute respiratory syndrome (SARS-CoV-2) [1]. Cigarette smoking affects nearly every organ in the body, compromises the immune system, and is associated with increased risk for pulmonary infections [3]. Smokers admitted to the hospital with SARS-CoV-2 are at a higher risk for complications and death from the respiratory COVID-19 virus [4], although some evidence suggests that nicotine may have a protective effect against initial COVID-19 infection [5-7]. Conditions such as lung disease, heart disease, diabetes, and obesity are all associated with tobacco use, and are linked with higher rates of hospitalization and mortality from COVID-19 infection [8,9]. Thus, tobacco use remains a serious concern during the pandemic. 
The pandemic has abruptly changed the way people live by way of social distancing, abiding by stay-at-home orders, quarantining, and by the shutting down of businesses and social gatherings. These circumstances provoked by the pandemic have resulted in increased stress and anxiety over an uncertain future $[10,11]$. Given that tobacco use is influenced by negative affective states such as stress [12-14], environmental conditions that facilitate or restrict cigarette access and use [15], and harm perceptions [16,17], it is important to understand tobacco use changes in response to the pandemic. For example, the threat of COVID-19 could result in negative consequences such as increased tobacco use, or users could have a renewed interest in quitting as a proactive step to improve their health. Historically, other national disasters have resulted in relapse in former smokers or increase in smoking among current smokers [18-21]. Additionally, evidence suggests an increased interest in cessation assistance among smokers after experiencing natural disasters [21].

As most studies related to tobacco use during the COVID-19 pandemic have mainly focused on the epidemiological evidence for estimates of infection and disease, research on tobacco use changes due to the pandemic in the United States (U.S.) is currently limited. An analysis of mostly non-daily dual cigarette and e-cigarette users found that approximately $30 \%$ increased their product use while others reduced use [22]. Among college students, campus closures related to COVID-19 were associated with reduced tobacco use frequency (i.e., days) but not actual quantity [23]. Finally, a multi-country study that included the U.S. found that there was a stronger desire to quit smoking or vaping if someone had a direct experience with COVID-19, such as someone in their household testing positive [24].

Our study aimed to build on this evidence detailing the behavior changes of tobacco users in central Pennsylvania during the onset of the pandemic. We evaluated the behavior changes and perceptions among current tobacco users during the COVID-19 pandemic using an online survey. This included evaluating the frequency of use, reasons for changes in use, and attempts to quit. Unique to this study, we evaluated qualitative data to further elucidate reasons for changes in use. It is important to characterize these changes as they could identify opportunities or barriers to tobacco cessation during these times of economic, psychological, and social hardships. We also evaluated perceptions of COVID-19 health risks, as they could be related to tobacco use behavior changes.

\section{Materials and Methods}

\subsection{Participants}

Survey respondents were a convenience sample of members in a tobacco user research registry who agreed to be contacted for future tobacco-related research at the Penn State College of Medicine. Participants were recruited from the central Pennsylvania area using postal flyers, social media, bus advertisements, and word of mouth. Participants were entered into the registry from August 2015 to April 2020. Email invitations with a unique survey link were sent to the participants in this registry on 23 April 2020. This was approximately one month after the Pennsylvania governor ordered the temporary closure of all non-life-sustaining businesses and issued the first stay-at-home orders. Two subsequent reminder emails were sent weekly to those who did not respond to the initial invitation.

Emails were sent to a total of 3396 valid email addresses and 406 (12.0\%) participants completed the survey. Participants included in the analysis were those who reported either current cigarette or e-cigarette use pre-COVID. In addition, all participants included were at least 21 years of age and could read and write in English. Participants were removed from analysis for the following reasons: pre-COVID tobacco use was not reported $(n=79)$, reported no current tobacco use pre-COVID $(n=31)$, not a cigarette or e-cigarette user pre-COVID $(n=2)$, or not reporting tobacco use status during COVID $(n=3)$. This resulted in $291(291 / 3396 ; 8.6 \%)$ participants for analysis. This research was approved by the Penn State College of Medicine Institutional Review Board (IRB). 


\subsection{Study Procedures}

Upon clicking the unique survey link, participants were provided with a summary of the research. Participants provided implied consent by clicking to continue with the survey. All responses to the survey were anonymous. Participants did not receive an incentive for their participation. Participants were asked a series of questions about their experiences with COVID-19 including any symptoms that they experienced. Participants were asked, "Starting in March 2020, we all became aware of an infectious virus (Coronavirus or COVID-19) that has spread across the country and the world. At any point in time from February 2020 onwards, did you experience symptoms that made you believe you may have contracted the virus?" Participants reporting symptoms were asked to report all the symptoms that they experienced (check all that apply), whether they had been tested (yes/no), and what the test results were (positive/negative/pending). Participants were also asked to rate their perception of risk using two questions, "How do you perceive your risk of catching COVID-19 compared with those who do not use tobacco or nicotine products?" and "If you were to catch COVID-19, how do you perceive your risk of suffering serious complications compared with those who do not use tobacco or nicotine products?" Response options for both questions were much less likely, less likely, the same, more likely, and much more likely.

Participants were then asked a series of questions about their tobacco use. First, participants were asked to report on their tobacco use prior to the COVID-19 pandemic by asking, "Which of the following products did you use just prior to March 2020 (before the COVID-19 pandemic)?" Participants were instructed to select all products used from the following list: cigarettes, e-cigarettes/vape pens, cigars, pipes, snus/snuff/dip/chew, hookah/waterpipe, or dissolvables. Then, participants were asked to report on their tobacco use at the time of the survey (during the COVID-19 pandemic) by asking, "Do you currently use cigarettes, electronic cigarettes/vape pens, cigars, pipes, snus/snuff/dip, chew, hookah/waterpipe, or dissolvables?". If participants endorsed a product, they were asked how many times per day they used the product. For e-cigarettes, a single "use time" was defined as approximately 15 puffs or $10 \mathrm{~min}$ of use. We asked participants the type of e-cigarette device currently used, from cigalike, advanced, mod, and pod-mod devices [25]. Additionally, participants were asked, "Did you change devices in response to the COVID-19 pandemic?" (yes/no). Those who responded yes were asked to describe the change (What device did you use? What do you use now? Why did you switch?).

Changes in use were evaluated by comparing product use times (per day) before and during the pandemic. Reasons for increases and decreases in use were assessed with two separate multiple choice questions (quantitative data). In addition, participants were asked an open-ended question to gain qualitative feedback about how COVID-19 has affected their tobacco use, "How has the COVID-19 pandemic affected your tobacco or nicotine products use? Please describe."

Participants were also asked a series of questions about quitting their tobacco/nicotine product use, including questions about the importance of quitting and their confidence in doing so. Participants were asked, "How important is it to you to stop tobacco or nicotine products use now?" and "How confident are you that you will succeed in stopping your tobacco or nicotine products use now?" Response options ranged from 1 (not at all) to 10 (extremely). Finally, participants were asked whether they had made any quit attempts during the COVID-19 pandemic and whether their quit attempt was driven by their desire to reduce their risk for COVID-19. Participants were asked, "Have you made or are you making an attempt to quit your tobacco or nicotine products use during the COVID-19 pandemic?" (yes/no), and if yes, "Was your quit attempt motivated by a desire to reduce your risks from the Coronavirus?" (yes/no). Those who attempted to quit were asked to report the methods used to quit. All survey questions and response choices can be accessed from the Survey Questionnaire Supplement (File S1). 


\subsection{Data Analysis}

Means and frequencies were used to describe the sample demographics, COVID-19related questions, and perceptions of COVID-19 risk. Linear regression models were used to predict perception of COVID contraction risk and COVID perception of complications risk. Independent variables included in these models were demographics (gender, age, race, ethnicity, education), COVID symptoms (yes/no), cigarette use (yes/no), e-cigarette use (yes/no), and importance and confidence to quit.

McNemar's tests were used to evaluate changes in the proportion of users reporting cigarette and e-cigarette use (yes/no) from pre-COVID to during the COVID-19 pandemic. Paired t-tests were used to evaluate within-subject changes in cigarettes smoked per day and e-cigarette times per day pre- to during COVID-19. Frequencies described the proportion of users who increased and decreased their use and their reasons for changes in use. Finally, a logistic regression model was used to predict attempting to quit. Independent variables included demographics, COVID symptoms (yes/no), cigarette use (yes/no), ecigarette use (yes/no), importance and confidence to quit, and perception of contraction and complications risk.

A figure was generated to describe overall changes in tobacco use from pre-COVID to during COVID. For this figure, participants were classified into groups based on the tobacco products that they reported using pre- and during COVID. Exclusive cigarette smokers were those who reported only use of cigarettes, while exclusive e-cigarette users were those who reported only use of e-cigarettes. Dual users were those who reported use of both cigarettes and e-cigarettes. Products other than cigarettes or e-cigarettes were classified in a category as other which included cigars, pipes, or chew.

Qualitative data from the open-ended question regarding how the pandemic has affect tobacco use were in the form of brief comments. Comments were grouped together into general themes and sub-themes (if necessary). The themes derived from the open-ended question and example quotes are provided below.

\section{Results}

Participants $(n=291)$ were $25.6 \%$ male, $93.4 \%$ white, and $21.7 \%$ earned a college degree or greater. Participants had a mean age of $47.3(\mathrm{SD}=11.6)$ years and smoked for an average of 27.5 years $(\mathrm{SD}=12.1)(n=267)$ at the time of survey. Nearly all participants were from Pennsylvania $(98.9 \%)$. Overall, $21.7 \%$ of participants $(n=63)$ reported symptoms that they believed to be caused from COVID-19 starting from February 2020 onward. Among those who reported symptoms $(n=63)$, the most commonly reported symptoms were headache $(66.7 \%)$, dry cough $(66.7 \%)$, body aches $(60.3 \%)$, and shortness of breath $(49.2 \%)$. A total of $36.5 \%$ reported mild symptoms, $60.3 \%$ reported moderate symptoms, and $3.2 \%$ $(n=2)$ reported severe symptoms requiring hospitalization. Of the 14 participants $(22.2 \%$ of those reporting symptoms) tested for COVID, 12 were negative $(85.7 \%)$, and 2 were still pending $(14.3 \%)$. The participants who reported severe symptoms requiring hospitalization did not report a test result. At the time of the survey, COVID-19 tests were not widely available, were generally for those experiencing symptoms or with known exposure, and the wait time for results was variable.

The majority of participants reported that they believed that their risk of contracting COVID-19 was the same as non-tobacco users $(67.3 \%)$, while $6.5 \%$ believed that their risk was lower and $26.2 \%$ believed that their risk was higher. Perceiving higher risk was associated with being female $(\beta=-0.29, p<0.01)$ and reporting greater importance for quitting ( $\beta=0.041, p<0.01$ ). A total of $57.7 \%$ believed that they were more at risk to suffer serious complications from COVID-19 if contracted, while $38.2 \%$ believed that their risk was the same, and $4.1 \%$ believed that their risk was lower. Perceiving higher risk for serious complications was associated with greater age $(\beta=0.01, p=0.01)$, being female $(\beta=-0.32, p<0.01)$, reporting greater importance for quitting $(\beta=0.09, p<0.01)$, and reporting lower confidence to quit $(\beta=-0.05, p=0.03$ ), 
Pre-COVID, 93.1\% ( $n=271$ ) of participants reported current use of cigarettes. During COVID, there was a significant decrease in the number of cigarette users $(90.4 \%)(n=263)$ $(p<0.01)$ (Table 1). There was an overall increase in the number of cigarettes smoked per day (CPD) among those who continued smoking pre- and during COVID-19 (Table 1). Among only the smokers who increased $(28.2 \% ; n=71)$, the number of cigarettes smoked per day rose from $13.3(\mathrm{SD}=6.7)$ to $18.9(\mathrm{SD}=8.9) \mathrm{CPD}(p<0.01)$. The top reasons for increasing use (quantitative data), among those who reported $(n=61)$, were stress $(82.0 \%)$, more time to smoke $(52.5 \%)$, and boredom $(11.5 \%)$. A total of $11.1 \%(n=28)$ decreased their use, from $18.8(\mathrm{SD}=7.2) \mathrm{CPD}$ to $9.8(\mathrm{SD}=5.5) \mathrm{CPD}(p<0.01)$. The top reasons for decreasing use (quantitative data), among those who reported $(n=19)$, were health reasons $(21.1 \%)$, schedule changes $(31.6 \%)$ and being around other non-smokers (i.e., children) (31.6\%). A total of $60.7 \%(n=153)$ had no change in CPD.

Table 1. Pre- and current tobacco use during the COVID-19 pandemic.

\begin{tabular}{cccc}
\hline & Pre- COVID-19 & During COVID-19 & $p$ Value \\
\hline Cigarette smoker \% (n) & $93.1(271 / 291)$ & $90.4(263 / 291)$ & $<0.01$ \\
Cigarettes per day & $15.4(7.7)(258)$ & $16.3(8.4)(253)$ & $<0.01$ \\
$\quad$ Mean (SD) (n) & $16.2(47 / 291)$ & $13.1(38 / 291)$ & $<0.01$ \\
E-cigarette user \% (n) & $13.1(14.8)(32)$ & $16.4(16.3)(37)$ & 0.01 \\
Times used per day & & & \\
Mean (SD) (n) & &
\end{tabular}

There were 256 participants who gave qualitative responses on how the pandemic has changed their tobacco or nicotine product use. Themes derived from the qualitative responses are presented in Table 2.

There was also a decrease in the number of participants who reported e-cigarette use pre-COVID to during COVID (16.2\%, $n=47$ to $13.1 \%, n=38, p<0.01)$. Among the continued users, there was a significant increase in times per day from $13.1(\mathrm{SD}=14.8)$ $(n=32)$, to $16.4(\mathrm{SD}=16.3)(n=37)(p=0.01)$. The largest proportion of participants reported use of a pod-mod device $(48.7 \%, n=18)$, followed by mod devices $(35.1 \%, n=13)$, advanced $(8.1 \%, n=3)$, and cigalike devices $(8.1 \%, n=3)$. Of those who reported use of a pod-mod $(n=18)$, more than half reported use of a JUUL $(55.6 \%, n=10)$. Only one participant stated that they changed devices in response to the pandemic. However, the participant did not provide additional detail about what product they used prior to the pandemic or why they switched. Figure 1 displays the number and proportion of participants using each tobacco type and the proportion that transitioned in each category pre- and during COVID.

During the COVID-19 pandemic, participants reported that quitting was somewhat important (mean score 5.7) (SD = 3.0) $(n=275)$, but participants were not very confident in their ability to quit (mean score 2.8$)(\mathrm{SD}=2.3)(n=279)$. Approximately one-quarter of participants (24.5\%) $(n=71)$ reported making an attempt to quit during the pandemic, with approximately one-third $(33.8 \%)(n=24)$ of those who attempted to quit reporting that their reason for quitting was to reduce their risk from COVID-19. Those who experienced symptoms associated with COVID were not more likely to attempt to quit $(p=0.24)$. Variables significantly associated with making a quit attempt were greater importance ( $\beta=0.385, p<0.01)$ and greater confidence $(\beta=0.161, p<0.01)$ for quitting. Among those who made an attempt to quit $(n=71)$, the most commonly reported methods used to quit were cold turkey $(28.2 \%)$, use of medications such as Chantix or Wellbutrin $(26.8 \%)$, and use of nicotine-replacement therapies (NRT) (22.5\%). Of those who attempted to quit, seven $(9.9 \%)$ participants were successful in quitting all tobacco use (reported no tobacco use at the time of the survey), with three quitting cold turkey, two using NRT medications, and two using other medications. 
Table 2. Qualitative themes and responses regarding COVID-19-related tobacco use changes ${ }^{1}$.

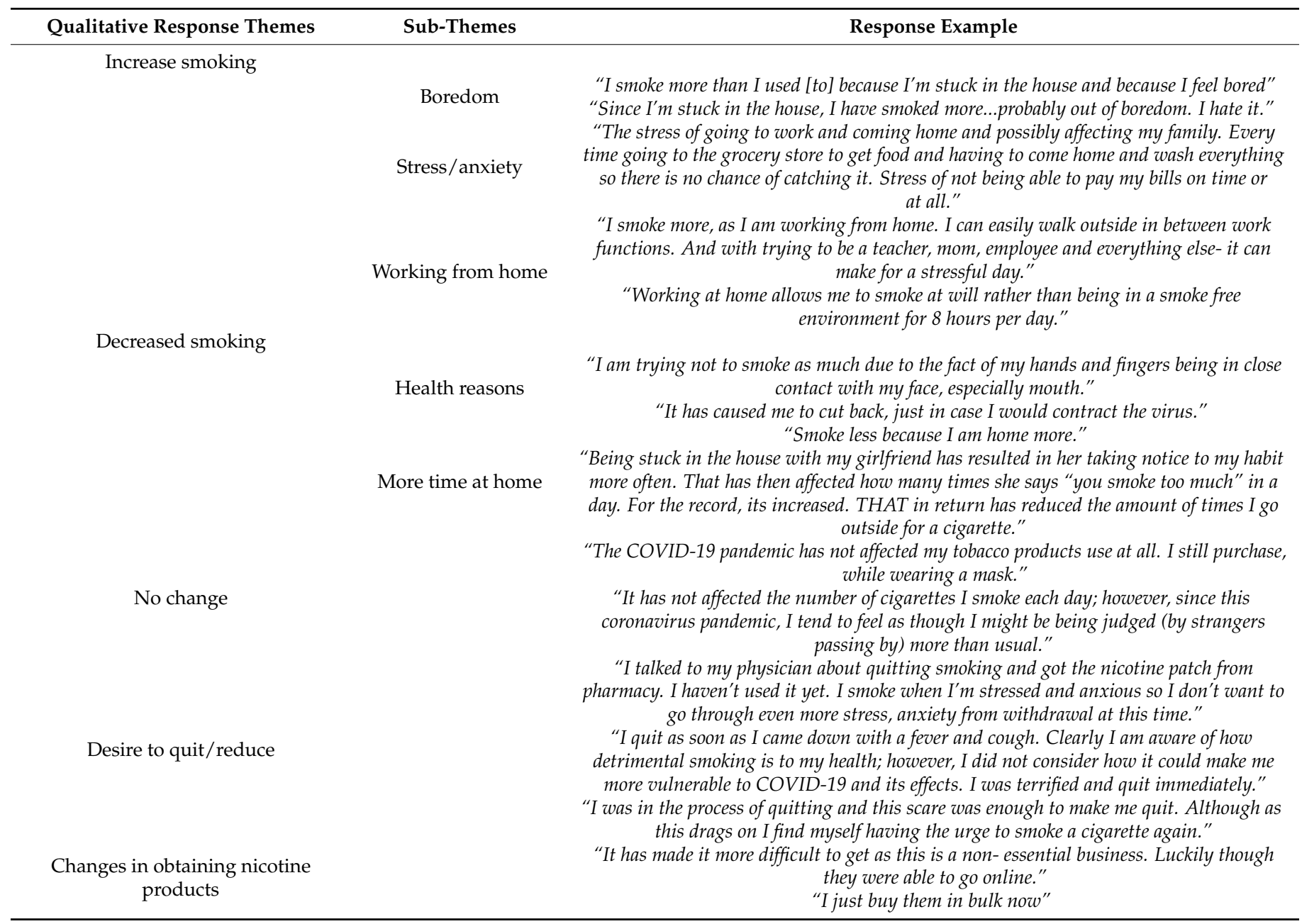

${ }^{1} 35$ participants did not provide a response.

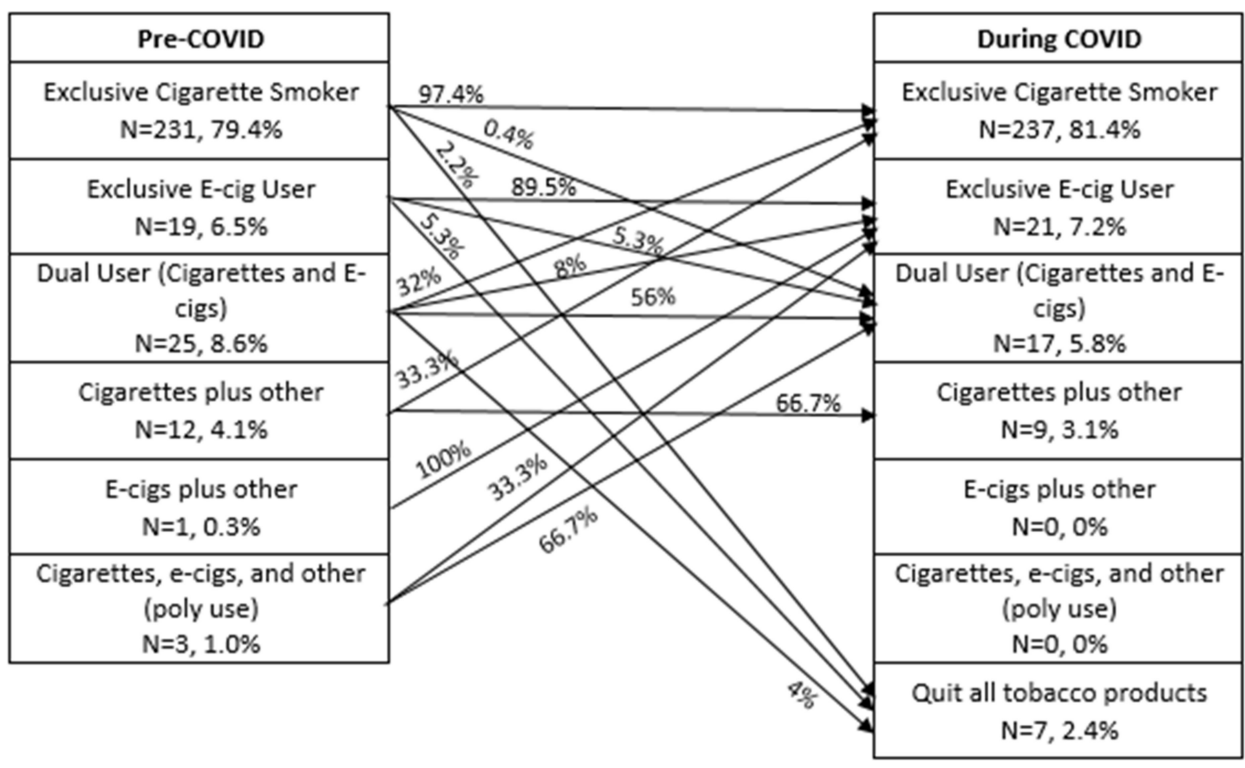

Figure 1. Pre-COVID-19 and during COVID-19 tobacco and nicotine use transitions. 


\section{Discussion}

The findings of this study provide preliminary insight into tobacco users' perceived threat of COVID-19 infection and how these beliefs influenced their tobacco use behaviors during the early stages of the COVID-19 pandemic. We found that many tobacco users have increased their tobacco use (both cigarette and e-cigarette use) in response to the COVID-19 pandemic. Increases in tobacco use have been reported across the globe [26-28]. This is concerning because preliminary evidence suggests that tobacco use leads to greater susceptibility to complications from COVID-19 [8,9]. In addition, greater use could lead to greater dependence [29], which may prolong use and make quitting more difficult. The most commonly reported reasons for increased use were stress, more time available to use tobacco (e.g., working from home), and boredom while quarantined. Other reports have found similar reasoning for increased cigarette [30] and e-cigarette use during the pandemic [31]. While many increased their tobacco use, others indicated attempting to quit in response to the pandemic, with seven $(7 / 291 ; 2.4 \%)$ achieving cessation. The majority of those who tried to quit reported doing so without using any FDA-approved medications. Quit success may be improved if more smokers use medications proven to increase the chance of achieving long-term abstinence [32]. It is known that many adults avoided medical care during the pandemic, even routine care which offers opportunities for discussions on tobacco use cessation [33]. Access to remote proven options for cessation such as home delivery of medications or tele-health counseling [34], as is being used in many other areas of medicine, would be well suited for tobacco treatment during the pandemic. In addition, as people are avoiding public settings, it should be considered how this affects social support systems such as group-based counseling.

The majority of participants reported that they believed their risk of contracting COVID-19 was the same as that for non-tobacco users and 58\% believed they were at a higher risk for suffering from serious complications compared to non-tobacco users. Perceptions of greater risks of both becoming infected and suffering severe complications were associated with an increased importance of quitting which suggests that smokers may be motivated to quit due to the threat of COVID-19. Smokers enrolled in smoking cessations trials during the pandemic reported that their motivation to quit was altered by the pandemic [35]. A study among smokers from the United Kingdom and Australia found that $45 \%$ of respondents wanted more information on smoking and COVID-19 health risks [36]. Health-based messaging on smoking and COVID-19 risk may be important during this time to capitalize on any increased interest in quitting among the population. Some messaging based on COVID-19 and quitting has been implemented [37]. The American Lung Association has provided guidelines for tele-health in the context of tobacco cessation [38].

The association of greater COVID-19 risk perceptions with greater importance in quitting fits into the theoretical framework of the Health Belief Model (HBM) [39,40]. The HBM is framed on a number of key health beliefs, such as perceived susceptibility, perceived severity, perceived benefits, perceived barriers, and self-efficacy that persuade individuals to make healthy behavior changes. The HBM has been used in previous studies to characterize response to health threats such as the swine flu, tuberculosis, and others [41-44]. Based on the framework, smokers who perceive themselves susceptible to a threat are more likely to engage in reduction or quitting behaviors. One-third of those who reported making a quit attempt during the pandemic in this study reported doing so to reduce their risk of COVID-19. However, many participants reported low confidence, or self-efficacy, in being able to quit, which highlights the importance of ongoing tobacco cessation messaging during this time. Preventative health interventions and messaging based on the HBM have been used in the past to increase a variety of healthy behaviors [45-48]. Cessation messaging and interventions within the context of the pandemic that are grounded in the HBM would be good opportunities for future research in order to increase self-efficacy and motivation to quit tobacco use at this time. 
The following limitations should be taken into consideration. The sample of tobacco users in this study were recruited from a tobacco user registry of individuals who are interested in participating in tobacco-related studies, so the sample is not nationally representative. However, our findings regarding patterns of data on use and quitting behaviors are consistent with those from two other recent studies around the same time period [22,24]. The low response rate could have been due to the lack of incentive for completing the survey. As this study was conducted during the pandemic when research activities were limited, biochemical validation of nicotine exposure and quitting was not performed. All responses were self-reported and may be subject to recall bias due to retrospective reporting. Causality cannot be determined regarding some of the identified associations given the survey was cross-sectional. Lastly, the data presented within this paper were collected at the beginning of the pandemic in the U.S. when lockdowns were being implemented and less information was known about the virus. Pennsylvania, like many other states in the surrounding area, was under strict social distancing rules with stay-at-home orders in place, mask mandates, and non-essential businesses and schools closed which directly influenced some of the responses we collected.

In conclusion, this study found that tobacco use increased among a sample of existing users during the COVID-19 pandemic. These results may have several implications for public health. Increased use is associated with higher dependence, exposure to tobaccorelated toxicants, and increased financial burden. Tobacco cessation efforts should not become underemphasized because of the pandemic. There is a need for innovative methods to support users who are interested in quitting during this particularly difficult time. The fact that many smokers are aware of their increased health risks of serious complications with COVID-19, are interested in quitting, and are spending more time at home suggests that smokers may be particularly receptive to pro-active telephone smoking cessation counseling during the pandemic.

Supplementary Materials: The following are available online at https:/ /www.mdpi.com/1660-460 1/18/4/1795/s1, File S1: COVID-19 Questions.

Author Contributions: Conceptualization, J.M.Y. and J.F.; methodology, J.M.Y.; formal analysis, J.M.Y.; investigation, J.M.Y. and N.M.K.; writing — original draft preparation, J.M.Y. and N.M.K.; writing - review and editing, J.M.Y., N.M.K., C.R.B., A.L.H., S.I.A., and J.F.; project administration, C.R.B. and J.M.Y. All authors have read and agreed to the published version of this manuscript.

Funding: The researchers are primarily funded by grants: R01DA048428, K23DA045081, and U01DA045517. The project was supported by the National Center for Advancing Translational Sciences, National Institutes of Health, through Grant UL1 TR002014.

Institutional Review Board Statement: This study was conducted according to the guidelines of the Declaration of Helsinki, and approved by the Institutional Review Board of the Penn State College of Medicine (IRB \#14949; date of approval 4-20-20).

Informed Consent Statement: Implied consent was obtained from all subjects involved in this study.

Data Availability Statement: The data presented in this study are available on request from the corresponding author.

Conflicts of Interest: J.F. has done paid consulting for pharmaceutical companies involved in producing smoking cessation medications, including GSK, Pfizer, Novartis, J\&J, and Cypress Bioscience. The other authors have no disclosures to report related to this publication.

\section{References}

1. Patel, A.; Jernigan, D.B. Initial Public Health Response and Interim Clinical Guidance for the 2019 Novel Coronavirus Outbreak United States, December 31, 2019-February 4, 2020. MMWR. Morb. Mortal. Wkly. Rep. 2020, 69, 140-146. [CrossRef]

2. Coronavirus Resource Center, Johns Hopkins University. Available online: https://coronavirus.jhu.edu/ (accessed on 28 December 2020).

3. Office of the Surgeon General (US). Office on Smoking and Health (US). The Health Consequences of Smoking: A Report of the Surgeon General; Centers for Disease Control and Prevention (US): Atlanta, GA, USA, 2004. 
4. Alqahtani, J.S.; Oyelade, T.; Aldhahir, A.M.; Alghamdi, S.M.; Almehmadi, M.; Alqahtani, A.S.; Quaderi, S.; Mandal, S.; Hurst, J.R. Prevalence, Severity and Mortality associated with COPD and Smoking in patients with COVID-19: A Rapid Systematic Review and Meta-Analysis. PLoS ONE 2020, 15, e0233147. [CrossRef] [PubMed]

5. Simons, D.; Shahab, L.; Brown, J.; Perski, O. The association of smoking status with SARS-CoV-2 infection, hospitalisation and mortality from COVID-19: A living rapid evidence review with Bayesian meta-analyses (version 9). Qeios 2020. [CrossRef]

6. Farsalinos, K.; Barbouni, A.; Poulas, K.; Polosa, R.; Caponnetto, P.; Niaura, R. Current smoking, former smoking, and adverse outcome among hospitalized COVID-19 patients: A systematic review and meta-analysis. Ther. Adv. Chronic. Dis. $2020,11$. [CrossRef]

7. Paleiron, N.; Mayet, A.; Marbac, V.; Perisse, A.; Barazzutti, H.; Brocq, F.X.; Janvier, F.; Bertrand, D.; Bylicki, O. Impact of Tobacco Smoking on the risk of COVID-19.A large scale retrospective cohort study. Nicotine Tob. Res. 2021. [CrossRef]

8. Kim, L.; Garg, S.; O’Halloran, A.; Whitaker, M.; Pham, H.; Anderson, E.J.; Armistead, I.; Bennett, N.M.; Billing, L.; Como-Sabetti, K.; et al. Risk Factors for Intensive Care Unit Admission and In-hospital Mortality among Hospitalized Adults Identified through the U.S. Coronavirus Disease 2019 (COVID-19)-Associated Hospitalization Surveillance Network (COVID-NET). Clin. Infect. Dis. 2020. [CrossRef] [PubMed]

9. Ko, J.Y.; Danielson, M.L.; Town, M.; Derado, G.; Greenlund, K.J.; Daily Kirley, P.; Alden, N.B.; Yousey-Hindes, K.; Anderson, E.J.; Ryan, P.A.; et al. Risk Factors for COVID-19-associated hospitalization: COVID-19-Associated Hospitalization Surveillance Network and Behavioral Risk Factor Surveillance System. Clin. Infect. Dis. 2020. [CrossRef]

10. Paredes, M.R.; Apaolaza, V.; Fernandez-Robin, C.; Hartmann, P.; Yañez-Martinez, D. The impact of the COVID-19 pandemic on subjective mental well-being: The interplay of perceived threat, future anxiety and resilience. Pers. Individ. Differ. 2021, 170, 110455. [CrossRef] [PubMed]

11. Cullen, W.; Gulati, G.; Kelly, B.D. Mental health in the COVID-19 pandemic. QJM 2020, 113, 311-312. [CrossRef] [PubMed]

12. Kassel, J.D.; Stroud, L.R.; Paronis, C.A. Smoking, stress, and negative affect: Correlation, causation, and context across stages of smoking. Psychol. Bull. 2003, 129, 270-304. [CrossRef] [PubMed]

13. Russell, M.A.H.; Peto, J.; Patel, U.A. The classification of smoking by factorial structure of motives. J. R. Stat. Soc. Ser. A 1974, 137, 313-333. [CrossRef]

14. McKennell, A.C. Smoking Motivation Factors. Br. J. Soc. Clin. Psychol. 1970, 9, 8-22. [CrossRef] [PubMed]

15. Frazer, K.; Callinan, J.E.; McHugh, J.; van Baarsel, S.; Clarke, A.; Doherty, K.; Kelleher, C. Legislative smoking bans for reducing harms from secondhand smoke exposure, smoking prevalence and tobacco consumption. Cochrane Database Syst. Rev. 2016, 2, Cd005992. [CrossRef]

16. Keller, P.A.; D'Silva, J.; Lien, R.K.; Boyle, R.G.; Kingsbury, J.; O'Gara, E. Perceived harm of menthol cigarettes and quitting behaviors among menthol smokers in Minnesota. Prev. Med. Rep. 2020, 20, 101269. [CrossRef]

17. Costello, M.J.; Logel, C.; Fong, G.T.; Zanna, M.P.; McDonald, P.W. Perceived risk and quitting behaviors: Results from the ITC 4-country survey. Am. J. Heal. Behav. 2012, 36, 681-692. [CrossRef] [PubMed]

18. Parslow, R.A.; Jorm, A.F. Tobacco use after experiencing a major natural disaster: Analysis of a longitudinal study of 2063 young adults. Addiction 2006, 101, 1044-1050. [CrossRef]

19. Osaki, Y.; Maesato, H.; Minobe, R.; Kinjo, A.; Kuwabara, Y.; Imamoto, A.; Myoga, Y.; Matsushita, S.; Higuchi, S. Changes in smoking behavior among victims after the great East Japan earthquake and tsunami. Environ. Heal. Prev. Med. 2020, 25, 19. [CrossRef]

20. Vlahov, D.; Galea, S.; Ahern, J.; Resnick, H.; Kilpatrick, D. Sustained increased consumption of cigarettes, alcohol, and marijuana among Manhattan residents after September 11, 2001. Am. J. Publ. Health 2004, 94, 253-254. [CrossRef]

21. Lanctot, J.Q.; Stockton, M.B.; Mzayek, F.; Read, M.; McDevitt-Murphy, M.; Ward, K. Effects of Disasters on Smoking and Relapse: An Exploratory Study of Hurricane Katrina Victims. Am. J. Health Educ. 2008, 39, 91-94. [CrossRef] [PubMed]

22. Klemperer, E.M.; West, J.C.; Peasley-Miklus, C.; Villanti, A.C. Change in Tobacco and Electronic Cigarette Use and Motivation to Quit in Response to COVID-19. Nicotine Tob. Res. 2020, 22, 1662-1663. [CrossRef] [PubMed]

23. Sokolovsky, A.W.; Hertel, A.W.; Micalizzi, L.; White, H.R.; Hayes, K.L.; Jackson, K.M. Preliminary impact of the COVID-19 pandemic on smoking and vaping in college students. Addict. Behav. 2020, 115, 106783. [CrossRef]

24. Yach, D. Tobacco Use Patterns in Five Countries During the COVID-19 Lockdown. Nicotine Tob. Res. 2020, 22, 1671-1672. [CrossRef] [PubMed]

25. Galstyan, E.; Galimov, A.; Sussman, S. Commentary: The Emergence of Pod Mods at Vape Shops. Eval. Health Prof. 2018, 42, 118-124. [CrossRef] [PubMed]

26. Rolland, B.; Haesebaert, F.; Zante, E.; Benyamina, A.; Haesebaert, J.; Franck, N. Global Changes and Factors of Increase in Caloric/Salty Food Intake, Screen Use, and Substance Use During the Early COVID-19 Containment Phase in the General Population in France: Survey Study. JMIR Publ. Health Surveill. 2020, 6, e19630. [CrossRef]

27. Malta, D.C.; Szwarcwald, C.L.; Barros, M.B.A.; Gomes, C.S.; Machado, Í.E.; Souza Júnior, P.R.B.; Romero, D.E.; Lima, M.G.; Damacena, G.N.; Pina, M.F.; et al. The COVID-19 Pandemic and changes in adult Brazilian lifestyles: A cross-sectional study, 2020. Epidemiologia Serv. Saude Rev. Sist. Unico Saude Bras. 2020, 29, e2020407. [CrossRef]

28. Cancello, R.; Soranna, D.; Zambra, G.; Zambon, A.; Invitti, C. Determinants of the Lifestyle Changes during COVID-19 Pandemic in the Residents of Northern Italy. Int. J. Environ. Res. Publ. Health 2020, 17, 6287. [CrossRef] [PubMed] 
29. Oliver, J.A.; Foulds, J. Association Between Cigarette Smoking Frequency and Tobacco Use Disorder in U.S. Adults. Am. J. Prev. Med. 2020. [CrossRef] [PubMed]

30. Bommele, J.; Hopman, P.; Walters, B.H.; Geboers, C.; Croes, E.; Fong, G.T.; Quah, A.C.K.; Willemsen, M. The double-edged relationship between COVID-19 stress and smoking: Implications for smoking cessation. Tob. Induc. Dis. 2020, 18, 63. [CrossRef]

31. Soule, E.K.; Mayne, S.; Snipes, W.; Guy, M.C.; Breland, A.; Fagan, P. Impacts of COVID-19 on Electronic Cigarette Purchasing, Use and Related Behaviors. Int. J. Environ. Res. Publ. Health 2020, 17, 6762. [CrossRef]

32. United States Public Health Service Office of the Surgeon General; National Center for Chronic Disease Prevention and Health Promotion; Office on Smoking and Health. Publications and Reports of the Surgeon General. In Smoking Cessation: A Report of the Surgeon General; US Department of Health and Human Services: Washington, DC, USA, 2020.

33. Czeisler, M.E.; Marynak, K.; Clarke, K.E.N.; Salah, Z.; Shakya, I.; Thierry, J.M.; Ali, N.; McMillan, H.; Wiley, J.F.; Weaver, M.D.; et al. Delay or Avoidance of Medical Care Because of COVID-19-Related Concerns-United States, June 2020. MMWR Morb. Mortal. Wkly. Rep. 2020, 69, 1250-1257. [CrossRef]

34. Matkin, W.; Ordóñez-Mena, J.M.; Hartmann-Boyce, J. Telephone counselling for smoking cessation. Cochrane Database Syst. Rev. 2019, 5, Cd002850. [CrossRef]

35. Rosoff-Verbit, Z.; Logue-Chamberlain, E.; Fishman, J.; Audrain-McGovern, J.; Hawk, L.; Mahoney, M.; Mazur, A.; Ashare, R. The Perceived Impact of COVID-19 among Treatment-Seeking Smokers: A Mixed Methods Approach. Int. J. Environ. Res. Publ. Health 2021, 18. [CrossRef]

36. Pettigrew, S.; Jun, M.; Roberts, I.; Bullen, C.; Nallaiah, K.; Rodgers, A. Preferences for Tobacco Cessation Information and Support During Covid-19. J. Addict. Med. 2020, 14, e362-e365. [CrossRef] [PubMed]

37. Smokefree Action Coalition. Smoking and COVID-Quit for COVID. Available online: https://smokefreeaction.org.uk/ quitforcovid/ (accessed on 23 December 2020).

38. American Lung Association. Telehealth as a Vehicle to Support Tobacco Cessation. Available online: https://www.lung.org/ getmedia/0df40b1c-cca4-4f8d-b17f-1c0ef19052a1/telehealth-tobacco-cessation.pdf (accessed on 23 December 2020).

39. Rosenstock, I.M. The Health Belief Model and Preventive Health Behavior. Health Educ. Monogr. 1974, 2, 354-386. [CrossRef]

40. Champion, V.L.; Skinner, C.S. The health belief model. Health Behav. Health Educ. Theory Res. Pract. 2008, 4, 45-65.

41. Cummings, K.M.; Jette, A.M.; Brock, B.M.; Haefner, D.P. Psychosocial determinants of immunization behavior in a swine influenza campaign. Med. Care 1979, 17, 639. [CrossRef] [PubMed]

42. Guidry, J.P.D.; Carlyle, K.E.; LaRose, J.G.; Perrin, P.; Messner, M.; Ryan, M. Using the Health Belief Model to Analyze Instagram Posts about Zika for Public Health Communications. Emerg. Infect. Dis. 2019, 25, 179-180. [CrossRef]

43. Azizi, N.; Karimy, M.; Salahshour, V.N. Determinants of adherence to tuberculosis treatment in Iranian patients: Application of health belief model. J. Infect. Develop. Ctries. 2018, 12, 706-711. [CrossRef] [PubMed]

44. Guidry, J.P.D.; Austin, L.L.; O’Donnell, N.H.; Coman, I.A.; Lovari, A.; Messner, M. Tweeting the \#flushot: Beliefs, Barriers, and Threats During Different Periods of the 2018 to 2019 Flu Season. J. Prim. Care Community Health 2020, 11. [CrossRef]

45. Saghafi-Asl, M.; Aliasgharzadeh, S.; Asghari-Jafarabadi, M. Factors influencing weight management behavior among college students: An application of the Health Belief Model. PLoS ONE 2020, 15, e0228058. [CrossRef]

46. Didarloo, A.; Nabilou, B.; Khalkhali, H.R. Psychosocial predictors of breast self-examination behavior among female students: An application of the health belief model using logistic regression. BMC Publ. Health 2017, 17, 861. [CrossRef] [PubMed]

47. Champion, V.; Skinner, C.S.; Hui, S.; Monahan, P.; Juliar, B.; Daggy, J.; Menon, U. The effect of telephone versus print tailoring for mammography adherence. Patient Educ. Couns. 2007, 65, 416-423. [CrossRef] [PubMed]

48. Skinner, C.S.; Strecher, V.J.; Hospers, H. Physicians' recommendations for mammography: Do tailored messages make a difference? Am. J. Publ. Health 1994, 84, 43-49. [CrossRef] [PubMed] 